\title{
Clinical outcomes of combined aortic root replacement with mitral valve surgery
}

Tirone E. David, MD, Susan Armstrong, MSc, Manjula Maganti, MSc, and Leo Ihlberg, MD

Objective: This study was undertaken to examine the operative mortality and morbidity and late outcomes in patients who required combined aortic root replacement with mitral valve surgery.

Methods: These combined procedures were performed in 123 patients with a mean age of $51 \pm 16$ years; $67 \%$ were men. The aortic root pathology was an aneurysm in 76 patients and other disorders in 47 patients. The mitral valve pathology was degenerative disease in 62 patients and other diseases in 61 patients. Sixty-four patients (52\%) underwent previous cardiac surgery. The aortic valve was preserved in 21 patients, and the mitral valve was preserved in 67 patients; the remaining patients underwent valve replacement. In addition, 57 patients underwent other procedures. The mean follow-up was $4.9 \pm 4.3$ years and complete.

Results: The operative mortality rate was $6.5 \%$ (8 patients), and late mortality was 9.7\% (12 patients). Reexploration of the mediastinum for bleeding (15\%) and implantation of permanent pacemaker $(18 \%)$ were the most common postoperative complications. Urgent surgery and functional class IV were predictors of operative mortality by univariate analysis. Survival at 1,5 , and 10 years was $90.9 \% \pm 2.6 \%, 86.1 \% \pm$ $3.3 \%$, and $79.3 \pm 4.9 \%$, respectively. Six patients required reoperation. Freedom from reoperation at 1,5 , and 10 years was $100 \%, 96.4 \% \pm 2.5 \%$, and $85.7 \% \pm$ $6.4 \%$, respectively. At the latest follow-up, 98 patients were alive and free from reoperation; 92 patients were in functional classes 1 and 2, and 88 patients were free from any cardiac or valve-related complication.

Conclusion: Aortic root replacement combined with mitral valve surgery is a complex operation associated with high morbidity, but the operative mortality is reasonably low and the long-term outcomes are gratifying.

From the Division of Cardiovascular Surgery, of Peter Munk Cardiac Centre, Toronto General Hospital, and University of Toronto, Toronto, Ontario, Canada.

Received for publication Nov 4, 2007; revisions received Dec 26, 2007; accepted for publication Feb 18, 2008.

Address for reprints: Tirone E. David, MD, 200 Elizabeth St 4N457, Toronto, Ontario M5G 2C4, Canada (E-mail: tirone.david@ uhn.on.ca)

J Thorac Cardiovasc Surg 2008;136:82-7

$0022-5223 / \$ 34.00$

Copyright $\odot 2008$ by The American Association for Thoracic Surgery

doi:10.1016/j.jtcvs.2008.02.038
$\mathrm{R}$ eplacement of the aortic root with valved conduits and replacement of the aortic root with preservation of the native aortic cusps, such as in aortic valvesparing operations, are established surgical options to treat patients with aortic root aneurysms and other disorders of the aortic root. Degenerative diseases are the most common cause of aortic root aneurysm; consequently, a proportion of these patients will have associated mitral regurgitation caused by mitral valve (MV) prolapse. ${ }^{1,2}$ Thus, combined aortic root replacement (ARR) with MV surgery is not a rare operation. Moreover, there are increasing numbers of patients who underwent ARR and require reoperation for failed biologic valves or infective endocarditis with aortic root abscess and involvement of the MV. Add coronary artery disease to these patients, and the cardiac surgeon is faced with a serious technical challenge. ${ }^{3} \mathrm{Al}-$ though there are case reports on combined ARR with MV surgery and reference of MV surgery in series of longitudinal outcomes of ARR, ${ }^{2,4-8}$ we could not find an article that examined this issue in clinical cardiac surgery. This study is an analysis of the operative mortality and morbidity and long-term results of combined ARR with MV surgery.

\section{Patients and Methods}

A review of our clinical database disclosed 123 consecutive patients who underwent ARR combined with MV surgery from 1981 to July of 2007, although 97 operations were performed 


\section{Abbreviations and Acronyms}

$\mathrm{ARR}=$ aortic root replacement

$\mathrm{MV}=$ mitral valve

during the past decade. Our review ethics board approved this retrospective study. Table 1 shows the clinical profile of patients. Table 2 summarizes the pathology of the aortic root and MV. Table 3 shows the operative data. Only 12 patients underwent emergency operations because of sepsis, shock, or acute type A aortic dissection.

All operations were performed via a median sternotomy and cardiopulmonary bypass with mild hypothermia $\left(32^{\circ} \mathrm{C}-34^{\circ} \mathrm{C}\right)$ except in patients who required replacement of the transverse arch, in which case deep hypothermia was used. Myocardial protection was provided with cold blood cardioplegia delivered directly into the coronary arteries. Myocardial revascularization was performed first, followed by the MV procedure and finally the ARR. The mitral annulus had to be reconstructed with autologous or bovine pericardium in 22 patients because of dystrophic calcification of the mitral annulus (18 patients) or annular abscess (4 patients). All patients who had reconstruction of the mitral annulus also had MV replacement. MV repair was performed in all patients with degenerative disease of the MV or isolated dilation of the mitral annulus (67 patients). In patients who had previous aortic and MV replacement, the MV was approached through the aortic root and an incision in the dome of the left atrium. ${ }^{9,10}$ An aortic valve-sparing procedure was feasible in 21 patients: 8 remodelings of the aortic root and 13 reimplantations of the aortic valve. A Dacron graft with a valve was used to replace the aortic root in 50 patients, and a biologic root was used in 30 patients. The remaining 22 patients had a destroyed aortic annulus, and a tubular Dacron graft was tailored to fit in the annular defect and sutured directly to the interventricular septum, the intervalvular fibrous body, or the sewing ring of a prosthetic MV. Afterward, an aortic valve was implanted into this graft, and the coronary arteries were reimplanted. ${ }^{10}$ Eighteen patients also required tricuspid valve annuloplasty.

Patients who had combined aortic valve sparing with MV repair and those who had a tailored tubular Dacron graft to fit the abnormal annulus were followed prospectively at annual intervals. The remaining patients were followed irregularly up to 2005, but all patients except 1 surviving patient were contacted in the first 8 months of 2007. The follow-up for this report was closed on September 1, 2007. The mean follow-up was $4.9 \pm 4.3$ years (range, 0-16 years).

All data analyses were performed with SAS 8.1 Software (SAS Institute, Cary, NC). Categoric variables were analyzed with the chisquare or Fisher exact test and reported as frequencies or percentages. All continuous variables were reported as mean \pm standard deviation. The Kaplan-Meier method was used to calculate estimates for long-term survival and freedom from reoperation. All preoperative variables with a univariate $P$ value of less than .25 or those with known biologic significance but failing to meet this critical $\alpha$ level were submitted to the multivariable model for Cox regression analysis to determine the independent multivariable predictors of operative and late death. Variable retention criteria in the model were set at a $P$ value of .05 .
TABLE 1. Clinical profile of patients

\begin{tabular}{|c|c|}
\hline No. of patients & 123 \\
\hline \multicolumn{2}{|l|}{ Age (y) } \\
\hline Mean $\pm S D$ & $51.2 \pm 16.5$ \\
\hline Range & 17 to 80 \\
\hline \multicolumn{2}{|l|}{ Sex: } \\
\hline male & $82(67)$ \\
\hline \multicolumn{2}{|l|}{ Electrocardiogram: } \\
\hline Sinus rhythm & $86(70)$ \\
\hline Atrial fibrillation & $31(25)$ \\
\hline Heart block/pacemaker & $6(5)$ \\
\hline \multicolumn{2}{|l|}{ Associated diseases: } \\
\hline Diabetes & $10(8)$ \\
\hline Hypertension & $31(25)$ \\
\hline Hyperlipidemia & $18(15)$ \\
\hline Chronic obstructive pulmonary disease & 3 \\
\hline Renal failure/dialysis & 3 \\
\hline Peripheral vascular disease & 3 \\
\hline \multicolumn{2}{|l|}{$\begin{array}{l}\text { New York Heart Association functional } \\
\text { classification: }\end{array}$} \\
\hline Class I & $18(15)$ \\
\hline Class II & $23(19)$ \\
\hline Class III & $38(31)$ \\
\hline Class IV & $44(36)$ \\
\hline Marfan syndrome & 3 \\
\hline Previous cardiac surgery: & $64(52)$ \\
\hline AVR & $28(23)$ \\
\hline AVR + MVR or repair & $22(18)$ \\
\hline ARR & $5(4)$ \\
\hline AVR or repair + RAA & $4(3)$ \\
\hline RAA & 2 \\
\hline Repair of aortic valve + VSD & 2 \\
\hline Repair of tetralogy of Fallot & 1 \\
\hline \multicolumn{2}{|l|}{ Left ventricular ejection fraction: } \\
\hline$>60 \%$ & $40(32)$ \\
\hline $40 \%-59 \%$ & $58(47)$ \\
\hline $20 \%-39 \%$ & $23(19)$ \\
\hline$<20 \%$ & $2(2)$ \\
\hline \multicolumn{2}{|l|}{ Infective endocarditis: } \\
\hline Remote & $14(11)$ \\
\hline Active & $3(2)$ \\
\hline Abscess & $7(6)$ \\
\hline Coronary artery disease & $22(18)$ \\
\hline Tricuspid insufficiency & $18(15)$ \\
\hline
\end{tabular}

$S D$, Standard deviation; $A V R$, aortic valve replacement; $A R R$, aortic root replacement; $M V R$, mitral valve replacement; $R A A$, replacement of ascending aorta; VSD, ventricular septal defect. Percentages are shown in parentheses.

\section{Results}

The operative mortality rate was $6.5 \%$ ( 8 patients). The causes of operative mortality were low cardiac output syndrome in 5 patients, stroke in 1 patient, pneumonia in 1 patient, and ruptured abdominal aortic aneurysm in 1 patient. The cause of low cardiac output syndrome was believed to 
TABLE 2. Aortic and mitral valve pathology

Aortic root pathology:

Degenerative aneurysm

Aortic dissection

Porcelain aorta

Failed aortic root homograft

Previous AVR with patch enlargement of annulus

Aortic root/mitral annulus abscess

Small aortic annulus

$\geq 4$ previous AVRs

Aortic stenosis with normal root*

Aortic valve pathology:

Normal aortic cusps

Failed aortic valve homograft

Failed aortic bioprosthetic valve

Failed mechanical valve

Dysfunctional bicuspid aortic valve

Annuloaortic ectasia

Degenerative calcific

Rheumatic

Other connective tissue disorder

Aortic valve lesion:

None

Stenotic

Insufficiency

Mixed

MV pathology:

Degenerative

Rheumatic

Dystrophic calcification of mitral annulus

Annular dilation

Prosthetic valve dysfunction

Failed MV repair

MV lesion:

Stenotic

Insufficiency

Mixed

$A V R$ Aortic valve replacement: $M V$ mitral valve *Both patients underwent the Ross procedure. Percentages are shown in parentheses.

be preoperative septic shock secondary to an infected aortic root graft in 1 patient, perioperative myocardial infarction in 2 patients, and right ventricular failure in 2 patients (probably related to inadequate myocardial protection resulting from a nondominant right coronary artery). Table 4 shows the operative mortality in various subgroups of patients. Only urgent surgery $(P=.007)$ and preoperative functional class IV were associated with increased mortality by univariate analysis $(P<.0001)$. The operative mortality in patients who had previous cardiac surgery was higher than after firsttime surgery ( $9.4 \%$ vs $3.4 \%)$, but the difference did not reach statistical significance $(P=.178)$ because of sample size. There were no predictors of operative death by multivariate analysis.
TABLE 3. Operative data

No. Patients

Aortic root procedure:

Aortic valve sparing $21(17)$

Ross procedure

2 (2)

Valved conduit

$50(41)$

Custom conduit + valve

$22(18)$

Aortic root homograft

$9(7)$

Medtronic Freestyle bioprosthesis

$19(15)$

(Medtronic Inc, Minneapolis, Minn)

Aortic valve implanted:

Mechanical

58 (47)

Tissue

$44(36)$

MV procedure:

Reconstruction of the mitral annulus + MVR 22 (18)

MVR 34 (28)

MV repair $67(54)$

MV implanted:

Mechanical $36(29)$

Tissue 20 (16)

Pulmonary valve replacement 2 (2)

Tricuspid valve annuloplasty $\quad 18(15)$

Coronary artery bypass $22(18)$

Replacement of transverse aortic arch 15 (12)

Aortic clamping time (min \pm SD) $141 \pm 33$

Cardiopulmonary bypass time (min \pm SD) $\quad 171 \pm 49$

ICU length of stay (d \pm SD)

$4.7 \pm 7.0$

Hospital length of stay $(d \pm S D)$

$12.6 \pm 11.7$

$M V R$, Mitral valve replacement; $M V$, mitral valve; $S D$, standard deviation; $I C U$, intensive care unit. Percentages are shown in parentheses.

Postoperative complications were common. Reexploration of the chest for bleeding was performed in 18 patients. The bleeding was caused by coagulopathy in 11 patients, leaking anastomosis in 5 patients, a branch of a vein graft in 1 patient, and the bed of the internal thoracic artery in 1 patient. Ninety-seven patients $(79 \%)$ received blood transfusions $(5.6 \pm 5.3$ units/patient), and 39 patients $(32 \%)$ received fresh-frozen plasma or platelets. Tranexaminic acid was used in 69 patients, and aprotinin was used in 42 patients. There was no difference in the blood requirement or reexploration rates between patients who received these 2 antifibrinolytic agents. Implantation of permanent transvenous pacemaker for heart block was necessary in 22 patients, mostly after reoperation (18 patients). Four patients had a stroke ( 3 intraoperatively and 1 postoperatively), and 1 patient died. Two patients had perioperative myocardial infarction and died. Four patients had intra-aortic balloon pumps because of low cardiac output syndrome. One patient had new-onset renal failure. The length of intensive care stay and total hospital stay are shown in Table 3.

There were 12 late deaths: 3 cardiac related (congestive heart failure in all 3), 4 valve related (1 due to anticoagulantrelated hemorrhage, 1 due to structural valve deterioration, 
TABLE 4. Operative mortality

\begin{tabular}{|c|c|c|c|}
\hline Variable & $\begin{array}{c}\text { Patients at } \\
\text { risk }\end{array}$ & $\begin{array}{c}\text { Operative } \\
\text { deaths }\end{array}$ & $P$ value \\
\hline \multicolumn{4}{|l|}{ Age } \\
\hline$<51$ y & 54 & $2(3.7)$ & \\
\hline $51-69$ y & 50 & $4(8)$ & \\
\hline$>69 y$ & 19 & $2(10.5)$ & .500 \\
\hline \multicolumn{4}{|l|}{ Sex: } \\
\hline Male & 82 & $3(3.7)$ & \\
\hline Female & 41 & $5(12.2)$ & .070 \\
\hline \multicolumn{4}{|l|}{ Associated diseases: } \\
\hline Diabetes & 8 & $2(25)$ & .071 \\
\hline Hypertension & 31 & $3(9.7)$ & .407 \\
\hline Hyperlipidemia & 18 & $1(5.5)$ & .859 \\
\hline COPD & 3 & $1(33)$ & .056 \\
\hline Peripheral vascular disease & 3 & 0 & .643 \\
\hline Chronic renal failure & 3 & 0 & .643 \\
\hline Emergent/urgent surgery & 12 & $3(25)$ & .007 \\
\hline Functional class IV & 44 & $8(18)$ & .000 \\
\hline Active infective endocarditis & 10 & $2(20)$ & .077 \\
\hline Ejection fraction $<40 \%$ & 25 & $3(12)$ & .211 \\
\hline Previous cardiac surgery & 64 & $6(9.4)$ & .178 \\
\hline Coronary artery bypass & 22 & $2(4.5)$ & .681 \\
\hline \multicolumn{4}{|l|}{ Aortic valve: } \\
\hline Repaired & 21 & 0 & \\
\hline Replaced & 102 & $8(7.8)$ & .184 \\
\hline \multicolumn{4}{|l|}{ MV: } \\
\hline Repaired & 67 & $2(2.9)$ & \\
\hline Replaced & 56 & $6(10.7)$ & .083 \\
\hline
\end{tabular}

COPD, Chronic obstructive pulmonary disease (with forced expiratory volume at 1 second of less than 1); $M V$, mitral valve. Percentages are shown in parentheses.

and 2 due to endocarditis), and 5 due to other causes. The survival at 1,5 , and 10 years was $90.8 \% \pm 2.6 \%, 86.1 \% \pm$ $3.3 \%$, and $79.3 \% \pm 4.9 \%$, respectively. Figure 1 shows the Kaplan-Meier estimates of survival in all patients. Six

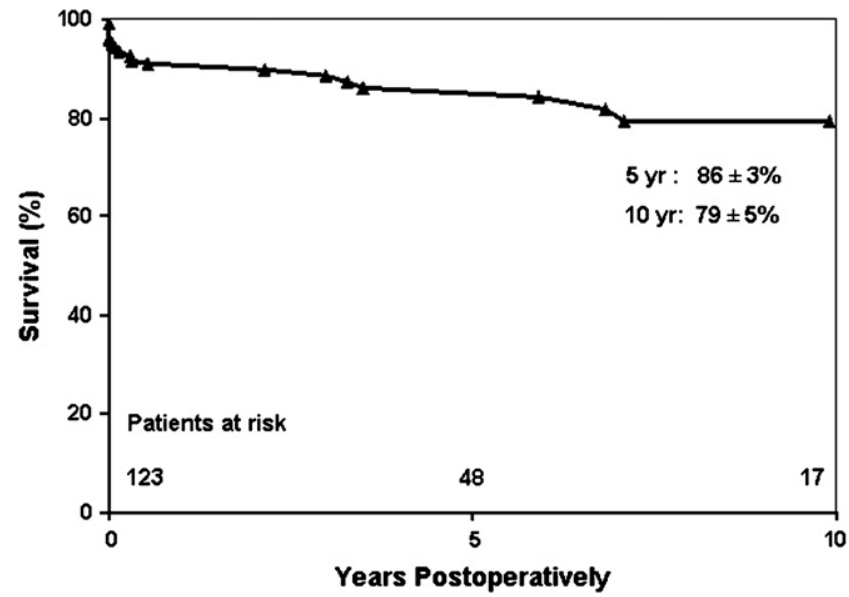

Figure 1. Kaplan-Meier estimates of survival after combined ARR and MV surgery. patients underwent reoperation for failure of aortic valve sparing (remodeling of the aortic root) (2 patients), dehiscence of the aortic prosthesis in a custom-made conduit (1 patient), prosthetic valve endocarditis (1 patient), structural valve deterioration (1 patient), and end-stage heart failure (heart transplant) (1 patient). All 6 patients survived reoperation. The freedom from reoperation at 1,5 , and 10 years was $100 \%, 96.4 \% \pm 2.4 \%$, and $85.7 \% \pm 6.4 \%$, respectively. Figure 2 shows the Kaplan-Meier estimates of freedom from reoperation.

Prosthetic valve endocarditis developed in 3 patients, 2 early and 1 late. Two patients were deemed inoperable and were managed with antibiotics alone and died. One patient underwent reoperation and survived. Five patients had major hemorrhagic complications; 1 patient died. Four patients had thromboembolic complications ( 1 stroke and 3 transient ischemic attacks). Valve degeneration developed in 2 patients with bioprosthetic valves (1 patient underwent reoperation and survived; 1 patient died in heart failure).

At the latest follow-up, 98 patients were alive and without reoperation, and in the following New York Heart Association functional classes: class I (76 patients), class II (17 patients), class III (5 patients), and class I (1 patient). Eighty-eight patients were free from any valve- or cardiacrelated event.

\section{Discussion}

Although aortic root aneurysm and mitral regurgitation caused by degenerative disease were the most common indications for combined ARR and MV surgery in this series, $38 \%$ of all patients had combined procedures for other pathologies, some as simple as aortic stenosis with mitral regurgitation treated with ARR with a pulmonary autograft and MV repair and others with complex problems, including multiple previous operations on both valves, aortic root abscess

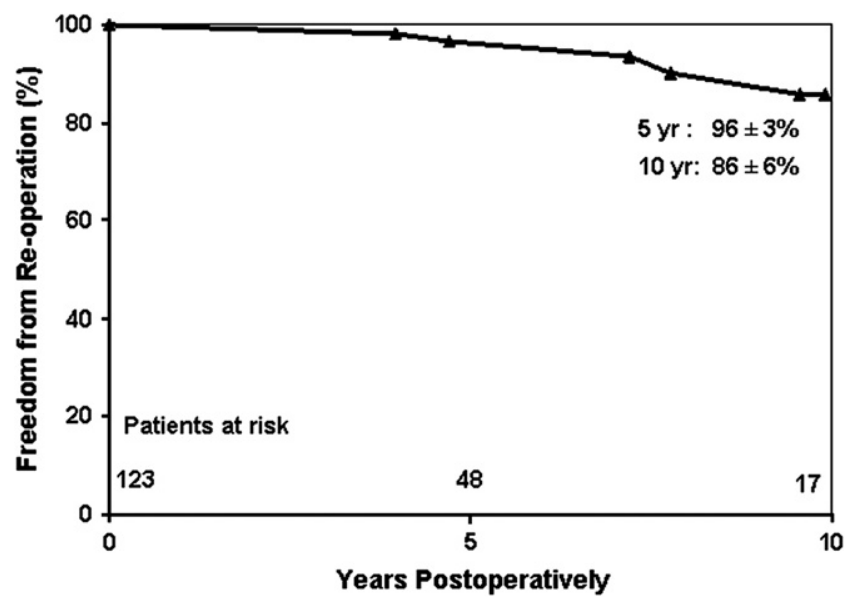

Figure 2. Kaplan-Meier estimates of freedom from reoperation after combined ARR and MV surgery. 
with extension into the mitral annulus, and dystrophic calcification of the mitral annulus with porcelain aortic root. Patch enlargement of the aortic annulus (4 Konno and 12 Manouguian procedures) had been performed in 16 patients, and the aortic root was so deformed at the time of reoperation that ARR was deemed appropriate. Five patients in this series had ARR because of a small aortic annulus. We have found ARR to be a better alternative than patch enlargement of the fibrous aortic annulus, particularly when the Medtronic Freestyle bioprosthesis (Medtronic Inc, Minneapolis, Minn) is used because it can be upsized. This variety of pathologies and the relatively small sample size of this series make assessment of operative risk and long-term results in the subgroups of patients with more complex aortic and MV disorders difficult.

It is clear that first-time ARR combined with MV repair or replacement is a safe operation and associated with a relatively low operative mortality (there were 2 deaths among 59 patients, for an operative mortality of $3.4 \%$ ). The operative mortality for patients who underwent previous cardiac surgery was higher at $9.4 \%$, although the difference did not reach statistical significance because of sample size. The lowest mortality occurred in patients who had first-time aortic valve sparing combined with MV repair, and the highest mortality was among patients who underwent previous operations on both valves and required complex reconstruction of the mitral annulus or aortic root.

Reexploration of the mediastinum for bleeding and implantation of pacemaker for heart block were the most common postoperative complications. Although most patients received an antifibrinolytic agent (tranexaminic acid or aprotinin), coagulopathy was still common, and $79 \%$ required blood transfusion and 32\% required fresh-frozen plasma and platelets. This was undoubtedly due to long cardiopulmonary bypass times and continued suction of blood from the pericardial cavity. Another common postoperative complication was heart block in patients who had previous operations and required complex reconstruction of the aortic root.

The addition of MV surgery to ARR requires a longer and more complex operation, but it does not seem to increase operative mortality. In a report by Gott and associates ${ }^{2}$ on the clinical outcomes of ARR on 271 patients with Marfan syndrome, combined MV surgery was necessary in 40 patients. There was no death among those 40 patients, and only advanced functional class and urgent surgery were predictors of early and late deaths in that series of 271 patients. On the other hand, Zehr and colleagues ${ }^{6}$ found that MV disease was an independent predictor of late death among 203 patients who had ARR, but only 13 patients had moderate or severe mitral regurgitation. As in Zehr and colleagues' series, most other reports on the clinical outcomes of ARR have a small number of patients with MV disease among those who underwent ARR. ${ }^{7,8}$ In a recent report from our institution on the outcomes of 452 patients who underwent ARR,
34 (8\%) had MV disease. ${ }^{11}$ MV disease had no effect on operative mortality or long-term survival in that study. ${ }^{11}$ The relatively high proportion of patients with MV disease in Gott and associates' series of ARR was because all patients had Marfan syndrome, in whom mitral regurgitation caused by degenerative disease is common. ${ }^{2}$ Byrne and colleagues ${ }^{3}$ found that the operative mortality for ARR was higher in patients who required coronary artery bypass surgery than in those who did not ( $21 \%$ vs $0.4 \%$ ), not necessarily because of the presence of coronary artery disease but because bypass surgery may be necessary in patients with more complex aortic root pathology or when technical problems with reimplantation of the right coronary artery occur. Coronary artery disease was an independent predictor of late deaths in a series of 452 patients who underwent ARR in our institution. ${ }^{11} \mathrm{~Pa}$ tients with dysfunctional bicuspid aortic valve may require $\mathrm{ARR}$, and because the right coronary artery is frequently nondominant, right ventricular protection during aortic clamping may be troublesome, which may have been the cause of operative death in 2 patients in the present series.

Crawford and Coselli ${ }^{4}$ reported on 6 patients with Marfan syndrome who had successful combined ARR and MV replacement. Those surgeons replaced the MV through the aortic root. Other surgeons have also used this surgical approach to repair the MV at the time of aortic valve-sparing operation or ARR. ${ }^{5,12}$

There have been case reports of patients with aortic root aneurysm in whom mitral regurgitation developed because of distortion of the anterior leaflet of the MV. ${ }^{13,14}$ In the present series, all patients had intrinsic MV disease (Table 2).

The 10-year survival in our series of combined ARR with MV surgery was $79 \%$. This long-term survival is similar to those reported for ARR for aneurysms of the aortic root and other pathologies. ${ }^{2,6,8,11}$ Gott and colleagues' series ${ }^{2}$ of ARR in patients with Marfan syndrome showed a 10-year survival of $81 \%$, Zehr and colleagues' series ${ }^{6}$ showed a 10 year survival of $79 \%$, and our series of 452 patients showed a 10-year survival of $74 \% .{ }^{11}$ Thus, the addition of MV surgery does not seem to worsen the long-term survival.

Reoperations were performed in 6 patients in our series of 123 patients who had combined ARR with MV surgery. Two patients underwent aortic valve replacement for failed aortic root remodeling; 1 patient underwent repair of prosthetic aortic valve dehiscence in a custom-made conduit; 1 patient underwent aortic valve replacement for failed bioprosthetic aortic valve in a custom-made conduit, 1 patient underwent ARR with aortic homograft and MV replacement for prosthetic valve endocarditis, and 1 patient underwent heart transplantation for end-stage heart failure. All patients survived reoperations. Valve-related complications (2 prosthetic valve endocarditis and 1 bioprosthetic valve failure) developed in 3 additional patients, which could have been managed surgically but were deemed inoperable because of several comorbidities. 
Other valve-related complications, such as anticoagulation-related hemorrhage and thromboembolic complications, were similar to those reported for patients with prosthetic valves.

\section{Conclusions}

The degree of complexity of combined ARR with MV surgery varies widely depending on the underlying pathology, but the operative mortality is reasonably low even in complex cases, and the long-term survival and clinical outcomes are excellent.

\section{References}

1. Chandraratna PA, Nimalasuriya A, Kawanishi D, Duncan P, Rosin B, Rahimtoola SH. Identification of the increased frequency of cardiovascular abnormalities associated with mitral valve prolapse by two-dimensional echocardiography. Am J Cardiol. 1984;54:1283-5.

2. Gott VL, Cameron DE, Alejo DE, et al. Aortic root replacement in 271 Marfan patients: a 24-year experience. Ann Thorac Surg. 2002;73:438-43.

3. Byrne JG, Karavas AN, Leacche M, et al. Impact of concomitant coronary artery bypass grafting on hospital survival after aortic root replacement. Ann Thorac Surg. 2005;79:511-6.

4. Crawford ES, Coselli JS. Marfan's syndrome: combined composite valve graft replacement of the aortic root and transaortic mitral valve replacement. Ann Thorac Surg. 1988;45:296-302.
5. Matsumoto H, Sakata R, Kinjo T, Iguro Y. Posterior mitral annuloplasty through the aortic root. Ann Thorac Cardiovasc Surg. 2005;11:264-6.

6. Zehr KJ, Orszulak TA, Mullany CJ, et al. Surgery for aneurysms of the aortic root: a 30-year experience. Circulation. 2004;110:1364-71.

7. Kindo M, Billaud P, Gerelli S, Levy F, Mazzucotelli JP, Eisenmann B. Twenty-seven-year experience with composite valve graft replacement of the aortic root. J Heart Valve Dis. 2007;16:370-7.

8. Etz CD, Homann TM, Silovitz D, et al. Long-term survival after the Bentall procedure in 206 patients with bicuspid aortic valve. Ann Thorac Surg. 2007;84:1186-93.

9. David TE, Kuo J, Armstrong S. Aortic and mitral valve replacement with reconstruction of the intervalvular fibrous body. $J$ Thorac Cardiovasc Surg. 1997;114:766-72.

10. Krasopoulos G, David TE, Armstrong S. Custom tailored valved conduit for complex aortic root pathology. J Thorac Cardiovasc Surg. 2008;135: 3-7.

11. Sioris T, David TE, Ivanov J, Armstrong S, Feindel CM. Clinical outcomes after separate and composite replacement of the aortic valve and ascending aorta. J Thorac Cardiovasc Surg. 2004;128:260-5.

12. Koizumi J, Nakajima T, Izumoto H, Ohsawa S, Ishihara K, Kawazoe K. Transaortic mitral valve repair combined with a modified Bentall procedure in a patient with Marfan's syndrome: report of a case. Surg Today. 2004;34:774-6.

13. Baek WK, Kim JT, Yoon YH, Kim KH, Kwan J. Huge sinus of Valsalva aneurysm causing mitral valve incompetence. Ann Thorac Surg. 2002; 73:1975-7.

14. Kioki M, Iedokoro Y, Kawamura J, Orii K, Masuda S, Tanaka S. Aneurysm of the left sinus of Valsalva causing aortic, mitral regurgitation and myocardial ischemia. Jpn J Thorac Cardiovasc Surg. 2000;48:476-9. 